\title{
Serial Dexamethasone Suppression Test in Psychiatric Inpatients
}

\section{Hai-Gwo Hwu and Hsin-Nan Lin}

A sample of 100 consecutively admitted cases were recruited to test the hypothesis that an abnormal dexamethasone suppression test (AbDST) is associated with decreasing clinical severity during the course of hospitalization in various diagnostic categories. Serial DSTs and psychopathological ratings were done at the end of the first and the third week postadmission, and 1 week before discharge. DST was also done at 1-year follow-up after discharge. The results of this study strongly suggest that a dual mechanism is responsible for the prevalence of AbDST. One is related to the global psychopathology of a nonspecific quantitative mechanism in various diagnostic categories. The other is a specific qualitative mechanism relating to the depressive state, as reflected in the higher prevalence of $A b D S T$ and more consistent AbDST results across different study time points in melancholia, and also in higher AbDST rates in disorders with higher depressive scores.

\section{Introduction}

It was reported by Carroll et al. (1981) that the dexamethasone suppression test (DST) was specific for the diagnosis of melancholia with a sensitivity of $67 \%$ and a specificity of $96 \%$. Carroll (1982a, 1982b) also asserted that DST has construct validity for depressive episodes, and has practical value in day-to-day psychiatric practice. Other independent research groups (Schlesser et al. 1979, 1980, 1981; Lewis and Winokur 1983) provide data to support the specific association of abnormal dexamethasone suppression test (AbDST) with depressive disc.der by showing a genetic contribution to the manifestation of AbDST in pure familial depressive disorders. However, the high prevalence rate of AbDST in other diagnostic categories (Abou-Saleh 1985; Baumgartner et al. 1985; Braddock 1986; Hwu et al. 1987) and its failure in differential diagnoses between primary and secondary depression (Hwu et al. 1985) have made researchers skeptical about the specificity of DST for depressive disorders.

A previous study (Hwu et al. 1987) of 164 Chinese psychiatric patients (including 53 melancholics, 60 schizophrenics, 12 with manic episodes, 20 other psychoses, and 19 neurotics) showed that the AbDST rates as assessed by Carroll's standard DST procedure (1982b) were $58.5 \%, 18.3 \%, 8.3 \%, 40.0 \%$, and $26.3 \%$ for melancholia, schizophrenia,

Address reprint requests to Hai-Gwo Hwu, Department of Psychiatry, Medical College, National Taiwan University Hiospitid, No. 1 Chang-Te Street, Taipei, Taiwan 10016, R.O.C.

From the Department of Psychiatry, Medical College, National Taiwan University Hospital, Taipei, Taiwan.

Received October 8, 1988; revised April 24, 1989. 
manic episode, other psychoses, and neuroses, respectively. The sensitivity of DST in Chinese melancholic patients was $58.5 \%$ and the specificity was $\mathbf{7 8 . 2 \%}$. These values were confirmed by another Taiwanese research group (Lu et al. 1988) and were compatible with the western literature (Carroll 1982b). Another previous study (Hwu et al. 1985) showed that the AbDST group was associated with a higher total Hamilton depression rating scale score (HDRS) and worse clinical severity, as assessed by the global assessment scale (GAS) (Endicott et al. 1976) score in both melancholia and schizophrenia. The psychotic score rated by combining delusion, hallucination, and incoherent speech was alsc associated with AbDST in schizophrenia and in the group of other psychoses, but not in melancholia. All these findings point to an association of AbDST with a severe degree of psychopathology either in depressive disorder or in other psychotic disorders.

A hypothesis can thus be proposed that the AbD\&T rates may be highest on admission, and may then decrease concomitantly with decreasing clinical severity during the hospitalization course in various diagnostic categories. This study was designed to test this hypothesis by serial DST in a group of 100 consecutively admitted psychiatric inpatients.

\section{Miethods}

One hundred consecutively admitted psychiatric inpatients under naturalist conditions, and with informed consent, were recruited for serial DST studies. The psychiatric diagnoses were based on DSM-III criteria (American Psychiatric Association 1980). The diagnostic procedure was carried out by a psychiatrist's diagnostic interview (Hwu 1986). This sample was composed of 49 (26 men, 23 women) schizophrenics, 21 (12 men, 9 women) manic episode subjects, 7 ( 3 men, 4 women) melancholics, 16 (6 men, 10 women) other psychoses, and 7 ( 1 man, 6 women) neurotics. The "other psychoses" group included 3 cases of organic brain syndrome, 4 paranoid disorders, 4 brief reactive psychoses, 1 schizophreniform disorder, and 4 atypical psychoses. The neurotics included 3 cases of generalized anxiety disorder, 3 conversion disorder, and 1 somatization disorder. Exclusion criteria for DST were applied as suggested by Carroll (1982b).

The means and the SDs for age were $25.2 \pm 6.8,28.6 \pm 13.8,47.9 \pm 16.0,34.8$ \pm 14.8 , and $32.6 \pm 21.4$, for schizophrenia, manic episode, melancholia, other psychoses, and neuroses, respectively. The means and SDs for years duration of illness were 4.6 \pm 4.5, 4.1 $\pm 4.1,4.2 \pm 7.3,3.6 \pm 5.6$, and $1.1 \pm 1.9$ for schizophrenia, manic episode, melancholia, other psychoses, and neuroses, respectively. All were admitted to the hospital because of inability to adjust to normal community life as a result of their psychopathology, and all were treated by the conventional inpatient treatment measures and combined biopsychosocial approach.

\section{DST Method}

One milligram dexamethasone was given at 11 PM per os on day 1. A 5-ml blood sample was taken on day 2 at $8 \mathrm{AM}, 4 \mathrm{PM}, 8 \mathrm{PM}$, and $11 \mathrm{PM}$ for cortisol measurement. The cortisol measurement was done with the $I^{125}$ cortisol RIA premix kit, provided by Diagnostic Products Corporation, Los Angeles, California. The inter- and intraassay coefficients of variation of the cortisol levels were $6.3 \%$ and $2.9 \%$, respectively. The result of DST is defined as abnormal if any of the postdexamethasone cortisol levels is $>\mathbf{5 . 0}$ $\mu \mathrm{g} / \mathrm{dl}$. Among Chinese, the abnormal DST rate is $10 \%$, as assessed by Carroll's (1982b) standard DST procedures with cutoff of $5 \mu \mathrm{g} / \mathrm{dl}$. 


\section{Assessment of Clinical Severity}

The severity of the clinical psychopathology was assessed with the Chinese versions (Hwu 1986) of the Hamilton Depressiun Rating Scale (HDRS) and the Monitoring Schedule of Psychiatric Inpatients (MSPI). The MSPI was constructed with 19 items to evaluate major clinical problems in psychiatric inpatients (Hwu 1986). These assessments were done blind to the DST results.

\section{Serial Study Design}

The DST and the assessments of MSPI and HDRS were performed at three successive time points for every patient during the hospitalization course. The first time point (A) was at the end of the first week after admission (DSTA); the second point (B) was set at the end of the third week after admission (DSTB); the third point (C) was 1 week before discharge (DSTC). At 1-year follow-up the DST was done (DSTF) with only one blood sample drawn at 4 PM the day after dexamethasone administration at 11 PM. DSTD was constructed to denote the DST result of the entire hospitalization course. If all DSTA, DSTB, and DSTC were normal, the DSTD was regarded as normal. If any one of these was abnormal, the DSTD was judged abnormal. The case numbers of DSTA, DSTB, DSTC, and DSTF were $100,78,45$, and 70, respectively. At time point B, 11 cases withdrew from study; 11 others returned home without notice to the research team. At time point $C 13$ cases had refused to participate, and 20 cases had been discharged, without notice to the research team. At time points $\mathrm{B}, \mathrm{C}$, and $\mathrm{F}$, the case numbers for schizophrenia were 38,26 , and 32 ; for manic episode 17, 9, and 18; for melancholia, 7, 3, and 5; for other psychoses 10, 6, and 10; and for neuroses 6, 1, and 5.

\section{Data Analyses}

AbDST rates in various diagnostic categories were analyzed in serial DST studies. Chisquare test was used for frequency data analyses. Yate's correction was adopted whenever applicable. Two-sided Student's $t$-tests were done for the parametric data. The statistical significance was set at $p<0.05$.

\section{Results}

The clinical condition of the patients got steadily better throughout the period of hospitalization for all diagnostic categories, as shown by decreasing MSPI scores (Table i). Table 2 shows that in the total sample the AbDST rates were highest in DSTA and lowest in DSTC. The AbDST rate of DSTF was similar to DSTC. In DSTD, the identically highest rates of 85.7\% of AbDST were found for both melancholia and for the neuroses. The schizophrenic and other psychotic patients both had relatively low AbDST rates, around $40 \%$ in the DSTD. The AbDST rate for the manic patients, $52.4 \%$, fell in between. The patterns of changing rates of AbDST in the course of hospitalization vere quite different for different diagnostic categories. The AbDST rate in schizophienia decreased markedly from time point $A$ to $B$. In the cases of manic episode, the AbDST rate increased from time point $A$ to $B$, then remained constant through time points $B$ and $C$. In melancholia, the AbDST rate decreased slightly from time point $B$ to $C$, but till remained at a rather high level. In the other psychotic or neurotic groups, the AbDST rates decreased 
Tabi: 1. Serial Assessments of Clinical Severity by the Monitoring Schedule of Psychiatric Inpatients (MSPI) and the Hamilton Depression Rating Scale (HDRS)

\begin{tabular}{|c|c|c|c|c|c|c|c|c|c|c|c|}
\hline \multirow[b]{3}{*}{ Group } & \multirow[b]{3}{*}{ Diagnosis } & \multirow[b]{3}{*}{$\begin{array}{l}\text { Rating } \\
\text { scale }\end{array}$} & \multicolumn{9}{|c|}{ Time points ${ }^{a}$} \\
\hline & & & \multicolumn{3}{|c|}{$\mathbf{A}$} & \multicolumn{3}{|c|}{ B } & \multicolumn{3}{|c|}{ C } \\
\hline & & & $\begin{array}{l}\text { Case } \\
\text { no. }\end{array}$ & Mean & SD & $\begin{array}{c}\text { Case } \\
\text { no. }\end{array}$ & Mean & SD & $\begin{array}{l}\text { Case } \\
\text { no. }\end{array}$ & Mean & SD \\
\hline \multirow[t]{2}{*}{1} & Schizophrenia & MSPI & 49 & 17.3 & 12.8 & 38 & 13.7 & 10.0 & 26 & 1.8 & 3.0 \\
\hline & & HDRS & & 7.8 & 6.7 & & 5.5 & 6.4 & & 1.1 & 1.6 \\
\hline \multirow[t]{2}{*}{2} & Manic & MSPI & 21 & 16.4 & 13.1 & 17 & 2.6 & 3.1 & 9 & 1.4 & 2.1 \\
\hline & episode & HDRS & & 2.8 & 4.1 & & 1.6 & 2.9 & & 0.6 & 0.9 \\
\hline \multirow[t]{2}{*}{3} & Melancholia & MSPI & 7 & 19.3 & 9.7 & 7 & 12.1 & 10.1 & 3 & 17.7 & 8.6 \\
\hline & & HDRS & & 25.0 & 10.2 & & 17.0 & 9.9 & & 14.3 & 12.4 \\
\hline \multirow[t]{2}{*}{4} & Other & MSPI & 16 & 17.9 & 12.5 & 10 & 6.6 & 7.0 & 6 & 0.4 & 0.6 \\
\hline & psychoses & HDRS & & 9.0 & 8.3 & & 7.7 & 12.2 & & 5.3 & 7.5 \\
\hline \multirow[t]{2}{*}{5} & Neurotics & MSPI & 7 & 10.7 & 7.9 & 6 & 5.8 & 7.3 & 3 & 0.3 & 8.4 \\
\hline & & HDRS & & 14.6 & 9.4 & & 8.6 & 6.5 & & 5.7 & 1.5 \\
\hline \multirow{2}{*}{\multicolumn{2}{|c|}{$\begin{array}{l}\text { Statistical analyses with } \\
\text { significant difference } \\
\text { between groups }\end{array}$}} & MSPI & - & & & Grour & $\& 4 v$ & & Group & vs 4 & \\
\hline & & HDRS & $\begin{array}{l}\text { Group } \\
\text { Group }\end{array}$ & $\begin{array}{l}\text { vs } 1,2,4 \\
\text { vs } 1\end{array}$ & & Groul & vs 1,2 & & - & & \\
\hline
\end{tabular}

${ }^{a} A$ and B: 1 and 3 weeks after admission; C: 1 week before discharge.

${ }^{b}$ Two-sided independent $t$-test. Significant level at $p<0.05$.

sharply from time point B to C. The AbDST rates of DSTF were around $40 \%$ for manic episodes, melancholia, and other psychoses. The schizophrenic group had only $9.4 \%$ with AbnST, and the neurotic group had none.

Table 3 illustrates the percentages with consistent DST results at three time points during the hospitalization course, and at 1-year follow-up for different diagnostic categories. As judged from the total sample, the consistent rates of DST results among different study time points were very similar and were around 65\%. The consistent AbDST rate was the highest between DSTA and DSTB. It was only about $8 \%$ to $9 \%$ between DSTC

Table 2. The Rates (\%) of Abnormal Dexamethasone Suppression Test (AbDST) at Different Siudy Time Points

\begin{tabular}{|c|c|c|c|c|c|c|c|c|c|c|}
\hline Diagnosis & $\begin{array}{c}\text { Case } \\
\text { no. }\end{array}$ & DSTA* & $\begin{array}{l}\text { Case } \\
\text { no. }\end{array}$ & DSTB* & $\begin{array}{l}\text { Case } \\
\text { no. }\end{array}$ & DSTC* & $\begin{array}{c}\text { Case } \\
\text { no. }\end{array}$ & DSTD* & $\begin{array}{l}\text { Case } \\
\text { no. }\end{array}$ & DSTF* \\
\hline Schizophrenia & 49 & 36.7 & 38 & $15.8^{\mathrm{a}}$ & 26 & 15.4 & 49 & $41.7^{b, c}$ & 32 & 9.4 \\
\hline Manic Episode & 21 & 19.1 & 17 & 41.2 & 9 & 44.4 & 21 & 52.4 & 18 & 38.7 \\
\hline Melancholia & 7 & 71.4 & 7 & $71.4^{4}$ & 3 & 66.7 & 7 & $85.7^{b, d}$ & 5 & 40.0 \\
\hline Other psychoses & 16 & 37.5 & 10 & 30.0 & 6 & 0.0 & 16 & $43.8^{\mathrm{d}, \mathrm{e}}$ & 10 & $\mathbf{4 0 . 0}$ \\
\hline Neurotics & 7 & 71.4 & 6 & 50.0 & 1 & 0.0 & 7 & $85.7^{c, e}$ & 5 & 0.0 \\
\hline Total sample & 100 & 38.0 & 78 & 30.8 & 45 & 22.3 & 100 & 50.0 & 70 & 21.4 \\
\hline
\end{tabular}

*DSTA, DSTB, DSTC: DST at the end of the first and third week after admission, and 1 week before discharge, respectively. DSTD was designed to include all DSTs in total hospitalization course. If any DSTA, DSTB, or DSTC was abnormal, then DSTD was abnormal. Normal DSTD means all of these three DSTs are normal. DSTF represents the DST at 1-year follow-up.

a,b.c,d,estatistically significant difference in abnormal DST rates between groups as indicated by the superscripts by $x^{2}$ statistics of contingence $(2 \times 2)$ tables. Statistical significance: ${ }^{a} p<0.01$; ${ }^{b, c, d, e p}<0.05$. 
Table 3. The Rates (\%) of Consistent Abnormal and Normal Dexamethasone Suppression Test (DST) Responses at Different Study Time Points

\begin{tabular}{|c|c|c|c|c|c|c|c|c|c|c|}
\hline \multirow[b]{2}{*}{ Diagnosis } & \multicolumn{2}{|c|}{ DSTA*'DSTB* } & \multicolumn{2}{|c|}{ DSTA*,DSTC* } & \multicolumn{2}{|c|}{ DSTB*/DSTC* } & \multicolumn{2}{|c|}{ DSTF*/DSTA* } & \multicolumn{2}{|c|}{ DSTF*/DSTD* } \\
\hline & $\begin{array}{c}\text { Abnor- } \\
\text { mal }\end{array}$ & Normal & $\begin{array}{c}\text { Abnor- } \\
\text { mal }\end{array}$ & Normal & $\begin{array}{c}\text { Abnor- } \\
\text { mal }\end{array}$ & Normal & $\begin{array}{c}\text { Abnor- } \\
\text { mal }\end{array}$ & Normal & $\begin{array}{c}\text { Abnor- } \\
\text { mal }\end{array}$ & Normal \\
\hline Schizophrenia & 10.5 & 63.2 & 4.0 & 56.0 & 4.3 & 65.2 & 4.5 & 45.5 & 3.0 & 51.5 \\
\hline Manic Episode & 5.9 & 47.1 & 22.2 & 55.6 & 11.1 & 22.2 & 5.6 & 50.0 & 16.7 & 27.8 \\
\hline Melancholia & 57.1 & 14.3 & 66.7 & 33.3 & 66.7 & 0.0 & 40.0 & 40.0 & 40.0 & 40.0 \\
\hline Other psychoses & 20.0 & 70.0 & 0.0 & 66.7 & 0.0 & 100.0 & 20.0 & 50.0 & 20.0 & 40.0 \\
\hline Neurotics & 33.3 & 16.7 & 0.0 & 0.0 & 0.0 & 100.0 & 0.0 & 25.0 & 0.0 & 25.0 \\
\hline Total sample & 16.7 & 52.5 & 9.3 & 55.8 & 8.1 & 56.8 & 8.5 & 52.9 & 11.4 & 40.0 \\
\hline
\end{tabular}

*Same as in Table 2.

and DSTA or DSTB. During hospitalization, the melancholia group showed the greatest tendency to consistent AbDST results. In schizophrenia and manic episodes, the likelihood of consistent AbDST was lowest in the initial 3 weeks; however, these two disorders were more likely to show consistently normal DST (NDST) than the melanchclics. At time point $B$ and $C$, the rate of inconsistent DST results was very high (66.7\%) for the manic patients. By combining the consistent AbDST and NDST results, it can be shown that all of these disorders had very similar percentages of consistent DST results, similar to those of the total sample. The analyses of consistent DST results between DSTF and the three time points DSTA, DSTB, DSTC, and the combined DST result of DSTD showed trends similar to those found at three time points of DSTA, DSTB, and DSTC.

The analyses of the variables of age and the duration of illnesses, loss of body weight, social economic status, and duration of hospitalization between the AbDST and NDST groups in each diagnostic category showed negative results.

\section{Discussion}

Serial DSTs were done on a series of consecutively admitted cases with similar levels of clinical severity across various diagnostic categories (Table 1). Methodologically, this study design was well suited for the observation of DST changes over the course of hospitalization and at 1-year follow-up in different diagnostic categories. Generally speaking, the AbDST rate decreased (Table 2) in the course of the study as the clinical condition improved (Table 1). It could be said that the AbDST was related to the olobal psychopathology in a quantitative way. This result confirms the finding of a higher AbDST rate in inpatients than in the outpatient populations (Hwu et al. 1987; Calloway et al. 1984), and confirms the finding that clinical severity of illness is an important factor for the frequency of AbDST (Baumgartner et al. 1986) in any serial DST study. The decrement of both AbDST rate and clinical severity score in the melancholic patients was not marked in the treatment course; this is due to the characteristics of this particular study sample of melancholia. In Taiwan, the melancholic patients and their families rsually refused admission unless the patients were seriously ill or had been ill for a very long time. This study used the consecutively admitted cases under naturalistic conditions. As a consequence, our group of melancholic patients was small in number, was in relatively serious clinical condition, and tended to be more resistant to treatment. 
At DSTA, the AbDST rate was highest in the melancholic and neurotic groups. These two groups had similar total HDRS scores, higher than those of the other groups. Higher HDRS scores have been repeatedly proven to be associated with higher AbDST rates (Hwu et al. 1987; Mendlewicz et al. 1982; Klein et al. 1984; Kasper and Bechman 1983; Maes et al. 1986; Kumar et al. 1986). However, the high AbDST rates of schizophrenia and other psychoses at DSTA cannot be explained simply by high HDRS scores; other psychopathological factors must be considered. It was found that a higher psychotic score also related to higher AbDST rates (Hwu et al. 1985), and this may explain the higher rates. In addition, it is also reasonable to consider the acute stress associated with the psychotic state and the hospitalization process. It is unusual that a manic episode, without conversion to a depressive state, showed a higher AbDST rate at DSTB than at DSTA. Besides, the rate of inconsistent DST results between DSTB and DSTC was the highest among all diagnostic categories. Joyce et al. (1987) reported that the manic state has a higher variability of cortisol level, a possible explanation for this unusual finding, which deserves some further attention. All these study results confirm Arana et al.'s (1985) assertion that DST is not reliable in differentiating severe melancholic depression, mania, and other psychoses. It can also be said that the DST cannot differentiate diagnoses among various disorders at an acute disturbance stage severe enough to require hospitalization. The AbDST rate for the total sample at DSTF was $21.4 \%$. In the sshizophrenic and neurotic groups, the AbDST rates were low and at the level of normal controls (Hwu et al. 1987). It was about $40 \%$ for the manic episode group, for melancholia, and for the other psychotic groups. The relatively high AbDST rate in these diagnostic categories deserves further investigation.

It is interesting to note that the DST results are more consistently stable for the NDST response. The consistency of AbDST between two time points seemed rather infrequent except for melancholic cases (Table 3). This finding indicates that the AbDST response is not a very dependable marker in psychiatric patients. As described in a previous report (Hwu et al. 1987), the rate of AbDST increased by increasing the number of sampling times. In the total sample, the rate of inconsistent DST responses between test time points varied between $30 \%$ and $40 \%$. The results relating to the consistency of DST responses between DSTD and DSTF are very important. As the DST response was not sufficiently consistent, the DSTD results might more accurately reflect the real nature of the status of DST response in the hospitalization course. This has also been reported in the literature by other researchers (Baumgartner et al. 1985; Baumgartner et al. 1986a; Baumgartner et al. 1986b) in serial DST studies. A study of the consistency between DSTD and DSTF results would provide more insight into the relationship between the DST and the disease course. The inconsistency rate was lowest in melancholia. The consistency rates between the DSTD and DSTF were around 40\%-60\% in schizophrenia, manic episode, and other psychoses. In melancholia, the consistency rate was $80 \%$; in contrast, it was only $25 \%$ in the neurotics. These data highlight the fact that the abnormal neuroendocrinologicai response of the H-P-A axis is unstable in the neurotic group, yet stable in the melancholic group. In groups with mania, schizophrenia, and other psychoses, the response has moderate stability. These data support the idea that DST responses might relate to specific disorders, especially melancholia, in a qualitative way in addition to the global quantitative, nonspecific relation to clinical severity as addressed above.

As suggested both by Baumgariner et al. (1986b) and by Abou-Saleh (1985), our study also strongly supports the view that the pathophysiological mechanisms mediating AbDST might well operate through two different mechanisms. One is related to the clinical state 
of depressive disorder as manifested by the higher prevalence and higher persistence of AbDST in severe melancholia, and also by the higher AbDST rate found in the disorders with high Hamilton depressive scores. Another mechanism is related to some nonspecific stress effect, including severe psychotic symptoms, the hospitalization process (Hwu et al. 1987), and other factors (von Zerssen et al. 1986, 1987). The manifestation of AbDST thus reflects the combined effect of these two mechanisms, each with differential contributing weight in inducing the AbDST. The differential weight of these two mechanisms may vary greatly in different diagnostic categories, at different stages of the clinical course, and under different stressful psychosocial conditions in any particular case. They may act cumulatively.

\section{References}

Abou-Saleh MT (1985): Dexamethasone suppression tests in psychiatry: Is there a place for an integrated hypothesis? Psychiatr Dev 3:275-306.

American Psychiatric Association (1980): DSM-III: Diagnostic and Statistical Manual of Mental Disorders, (ed 3). Washington, DC: American Psychiatric Press.

Arana GW, Ealdessarini TJ, Ornsteen M (1985): The dexamethasone suppression test for diagnosis and prognosis in psychiatry. Arch Gen Psychiatry 42:1193-1204.

Baumgartner A, Graf K-J, Kurten I (1985): Serial dexamethasone suppression test in psychiatric illness: Part 1. A study in schizophrenia and mania. Psychiatry Res 18:9-23.

Baumgartner A, Graf K-I, Kurten I (1986a): Serial dexamethasone suppression tests in psychiatric illness: Part 2. A study in major depressive disorders. Psychiairy Res 18:25-43.

Baumgartner A, Haack D, Vecsei P (1986b): Serial dexamethasone suppression tests in psychiatric illness: Part 3. The influence of intervening variables. Psychiatry Res 18:45-64.

Braddock L (1986): The dexamethasone suppression test-fact or artifact. Br J Psychiatry 148:363374.

Calloway SP, Dolan RJ, Fonagy P, De Soriza VFA, Wakeling A (1984): Endocrine changes and clinical profiles in depression: 1. The dexamethasone suppression test. Psychol Med 14:749758.

Carroll BJ (1982a): The dexamethasone suppression test for melancholia. Br J Psychiatry 140:292304.

Carroll BJ (1982b): Use of the dexamethasone suppression test in depression. J Clin Psychiatry 43:44-48.

Carroll BJ, Feinberg M, Greden JF, et al. (1981): A specific laboratory test for the diagnosis of melancholia-standardization, validation, and clinical utility. Arch Gen Psychiatry 38:15-22.

Endicott J, Spitzer RL, Fleiss JL, Cohen J (1976): The global assessment scale. Arch Gen Psychiatry 33:766-771.

Hwu HG (1986): Manual of Psychiatric Diagnosis. Taipei: Publication Committee, College of Medicine, National Taiwan University.

Hwu HG, Chen TS, Yang YY (1985): The clinical diagnostic value of dexamethasone suppression test in depressive illness. Ann Acad Med Singapore 14:104-109.

Hwu HG, Lin HN, Lu RB (1987): Dexamethasone suppression test in psychiatric diagnosis and psychopathology for Chinese patients. Proc Natl Sci Counc Repub China [A] Life Sci 11:164 174.

Joyce PR, Ronald RA, Elder PA (1987): Individual differences in plasma cortisol changes during mania and depression. J Affective Disord 12:1-5.

Kasper S, Bechman H (1983): Dexamethasone suppression test in a pluri-diagnostic approach: Its relationship to psychopathological and clinical variables. Acta Psychiatr Scand 68:31-37.

Klein HE, Bender W, Mayr H, Niederschweiberer A, Schmauss M (1984): The DST and its 
relationship to psychiatric diagnosis, symptoms and treatment outcome. Br J Psychiatry 145:591599.

Kumar A, Alcser K, Grunhaus L, Greden JF (1986): Relationships of the dexamethasone suppression test to clinical severity and degree of melancholia. Biol Psychiatry 21:436-444.

Lewis DA, Winokur G (1983): The familiar classification of primary unipolar depression: Biological validation of distinct subtypes. Compr Psychiatry 24:495-501.

Lu RB, Ho SL, Huang HC, Lin YT (1988): The specificity of the dexamethasone suppression test in endogeneous depressive patients. Neuropsychopharmacology 1:157-162.

Maes M, De Ruyter M, Hobin P, Suy E (1986): The dexamethasone suppression test, the Hamilton depression rating scales and the DSM-III depressive categories. J Affective Disord 10:207-214.

Mendlewicz J, Charles G, Franckson JM (1982): The dexamethasone suppression test in affective disorder: Relationship to clinical and genetic subgroups. Br J Psychiatry 141:464-470.

Schlesser MA, Winokur G, Sherman BM (1979): Genetic subtypes of unipolar primary depressive illness distinguished by hypothalamic-pituitary-adrenal axis activity. Lancet i:739-741.

Schlesser MA, Winokur G, Sherman BM (1980): Hypothalamic-pituitary-adrenal axis activity in depressive illness: Its relationship to classification. Aich Gen Psychiatry 37:737-743.

Schlesser MA, Winokur G, Sherman BM (1981): Dexamethasone suppression test and subtype of depression. Arch Gen Psychiatry 38:363-364.

von Zerssen D, Berger M, Doerr P (1987): Neuroendocrinological studies on depression with special reference to research at the Max-Planck-Institute of Psychiatry. Pharmacopsychiatry 20:8-22.

von Zerssen D, Berger M, Dose M, et al. (1986): The nature of neuroendocrine abnormalities in depression: A controversial issue in contemporary psychiatry. Psychiatr Dev 3:237-256. 